\title{
Enhanced 'BDABDC-DC' System For Vehicle To Grid Technology
}

\author{
N.Janaki, R.Krishna Kumar
}

\begin{abstract}
There is a wide range of functionalities, if $E V$ 's are connected to electric grid.EV is capable of both battery recharging and providing back energy to the grid. This is promoted as vehicle-to-grid(V2G) technology which is becoming more attractive in the era of e-mobility industry.Therefore, a bidirectional converter is needed to allow power flow in both directions at the regulated level.Hence,this effort analyses and compares the performance of 'BDABDC-DC' system in closed loop operation using 'proportional -integral' and 'Fractional order' PID controller. The simulation is carried out in Matlab Simulink. The responses of both the controllers on BDABDC-DC systems are compared and tabulated.
\end{abstract}

Keywords: 'Bidirectional Dual Active Bride DC-DC converter'(BDABDC-DC), -Vehicle-to-Grid, DC-Micro-grids, -Electric-Vehicles, Batteries, fractional-order- PID(FOPID), proportional-integral-controller(PI).

\section{INTRODUCTION}

Popularity of electric vehicle has increased due to degradation of fossil fuels. The most vital part of the EV is the charging system of battery which has been the area of interest in the field of research [1]-[5]. The main feature of EV is the benefit of V2G technology which allows the stored energy in the battery system to the grid network whenever there is a high demand. Other benefits of using V2G technology are regulated voltage, distributed generation and reactive power compensation. Thus, an EV needs a bidirectional battery charger to enhance the power flow in both the directions in a controlled manner[6]-[11].

Electric vehicles produce nearly zero carbon emission, provided that they are charged through renewable energy sources. Electric vehicles reduce our dependency on foreign oil .The bidirectional dc-dc converter along with energy storage has become a promising option for many power related systems, including hybrid vehicle, fuel cell vehicle, renewable energy system and so forth. It not only reduces the cost and improves efficiency, but also improves the performance of the system.

Revised Version Manuscript Received on 16 September, 2019.

* Correspondence Author

N.Janaki, EEE Department, Vels Institute Of Science, Technology And Advanced Studies, Chennai, India. Email: janakinarayanan4@gmail.com

Dr.R.Krishna Kumar, Professor/Head EEE Department, Vels Institute Of Science, Technology And Advanced Studies, Chennai, India. Email: hodeee@velsuniv.ac.in

\section{DUAL-ACTIVE ISOLATED BRIDGE CONVERTERS}

For high power density, isolated type BDABDC-DC system was proposed in [23]. This work focuses on in using dual active isolated bridge converter as it has less stress in components, zero voltage switching and bidirectional power flow. 'Dual Active Bridge' (DAB) is comprised of two bridges which are of ' $\mathrm{H}$ '-type and a high frequency transformer. This high frequency transformer provides galvanic isolation. Since both the bridge are active, the name dual active is given. As there are many differences in the inversion and rectification process such as 'PWM' technique, the commutation control of MOSFET can be done by generating square wave with a 50\% duty cycle .Moreover for high power applications square waves are more beneficial .When square waves are imposed on the windings of the transformer "dead' time for the voltage to go to zero is reduced, which in turn reduces the losses in the switch.

In [12]-[16], topologies and various control strategies of BDABDDC-DC was proposed. "-A-grid tied-PV framework comprising of measured-current fed-dual-active Bridge (CFDAB) dc-dc-converter with-MLI" was proposed by VenkateswaraRao [17]-[20]. In [14], new ideology on converter interfacing hybrid-appropriate -energy sources \& dc-bus" was proposed.

"PSM (Phase shift modulation) in addition to duty-proportion control had been connected to DAB-Converters to accomplish higher level of control freedom" [21]-[22].Diverse -regulation techniques were assessed and looked at. New -switching -techniques were displayed to diminish the switching misfortune and increment productivity of DAB-Converters. The above literature does not report the evaluation of PI and FOPID controlled for BDBA-BDDC system.

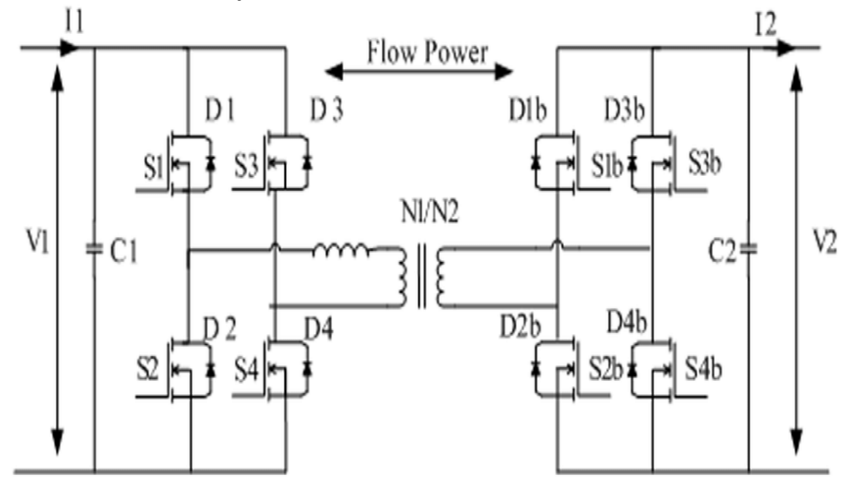

Fig 1. 'Isolated Type’ DAB DC-DC converter 


\section{SYSTEM-DESCRIPTION}

"-Block-diagram of BDABDC-DC" is appeared in Fig-2.Converter-1 acts as inverter in forward-mode of BDABDC-DC-system. $18 \mathrm{~V}$ is stepped up to $40 \mathrm{~V}$ using HF--Transformer. The "yield of HFT is converted to DC-using converter-2".

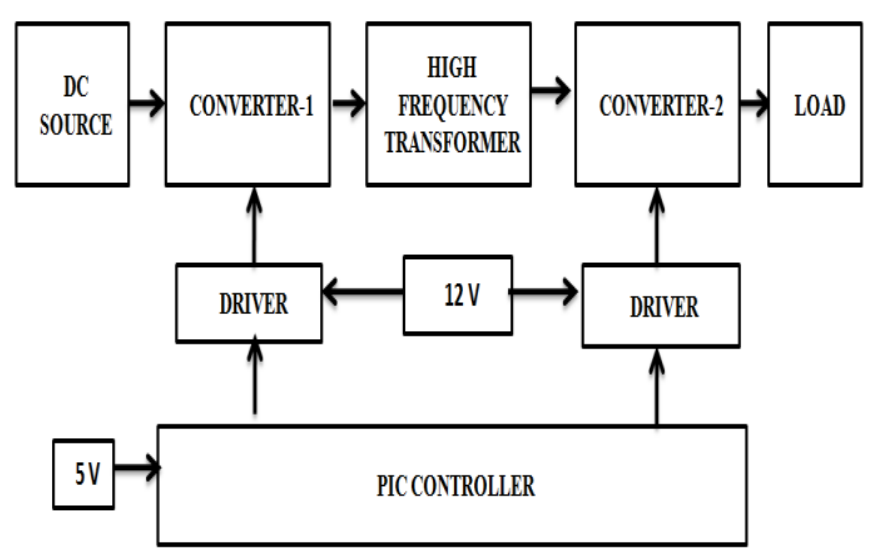

Fig-2. "-Block-diagram of BDABDC-DC System

\section{FOPID-CONTROLLER}

For the proposed system in the above block diagram, performance analysis is done for the BDABDC-DC converter by using 'PI' \& 'FOPID' controller. 'Fractional order Control, is a method that uses 'Fractional -order Integrator' which serves as a portion of 'control system design'. By adopting 'fractional calculus', we can improvise the method of strategy and control. This control serves better for the difficulties that occur due to the 'overshoot and resonance' condition. .By implementing 'fractional order control', we can attain a efficient response for the proposed system with improved dynamic response

\section{SIMULATION}

A "-Open-loop-BDABDC-DC with-Disturbance" "-Circuit-diagram of the Open-loop-BDABDC-DC with-disturbance" is appeared in Fig-3.

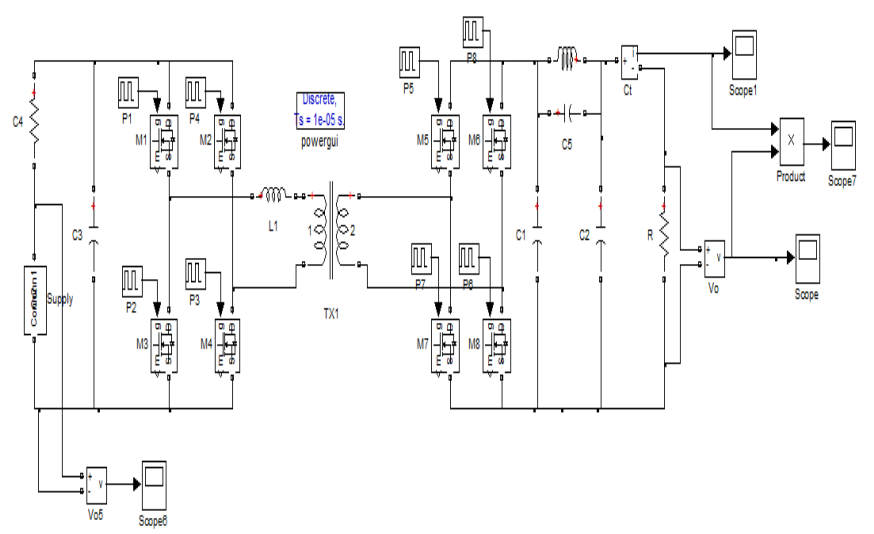

Figu-3. "-Circuit-diagram of Open-loop-BDABDC-DC converter with- Disturbance"
BDABDC-DC's Input side Voltage is appeared in Fig-4\&its- value is $18 \mathrm{~V}$.

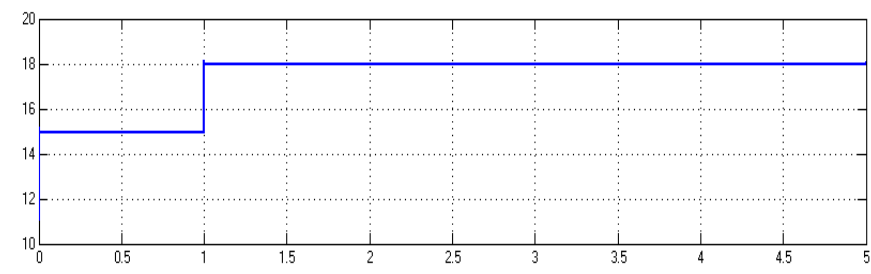

Figu-4 'Input-voltage'

'Output-voltage-across -RLoad of BDABDC-DC' is shown in Figu. $5 \& 40 \mathrm{~V}$ is its value.

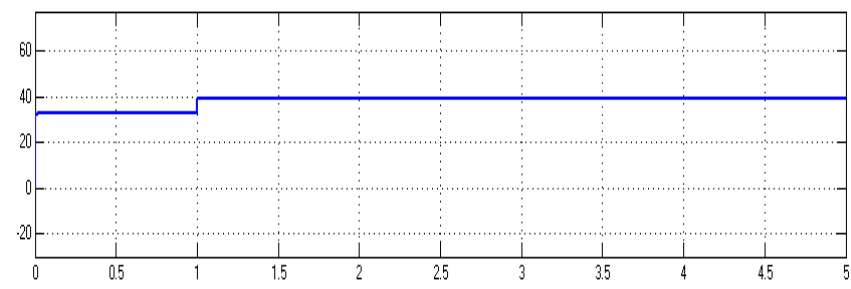

Figu-5. "-Output-voltage-across-R-Load"

"-Output-current through load of BDABDC-DC is appeared in Figu $-6 \& 0.065 \mathrm{~A}$ is its value.

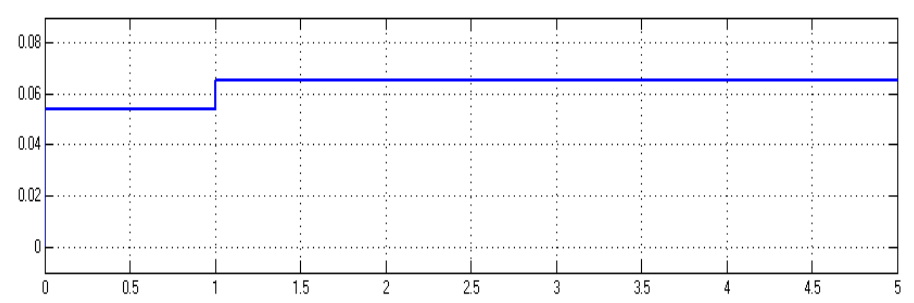

Figu-6. "-Output-current-through-load"

"-Output-power of BDABDC-DC is appeared in Figu-7\&2.7

Watts is the attained value.

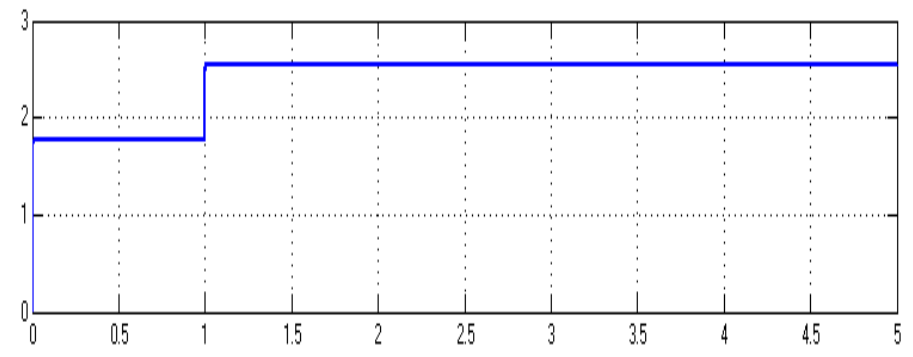

Figu-7. “-Output-power”

B Closed-loop-BDDABDDC with-PI-controller

Fig 8 shows the "-Closed-loop- BDABDC-DC with PI-controller". The value of voltage across the load is measured and evaluated with VRef. Comparison of these two parameters is the error which is fed to PI Controller. Response of PI is used to update the pulse-width of lower-MOSFETs. 


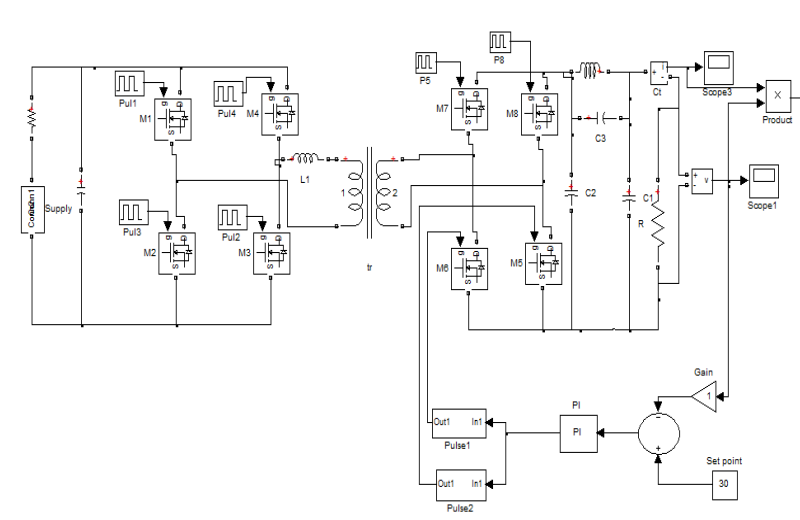

Figu-8. '-Closed-loop-BDDABDDC-with PI-controller'

The '-input-voltage of BDABDC-DC converter with PI-controller' is appeared in Fig 9 \&its value is $18 \mathrm{~V}$.

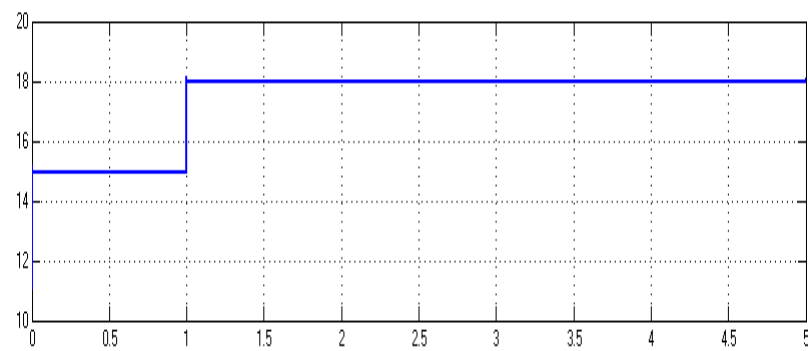

Figu-9. '-Input-voltage'

"-Output-voltage across-R-Load

of BDABDC-DC-converter with PI-controller” is appeared in Fig-10\&its-value is $34 \mathrm{~V}$.

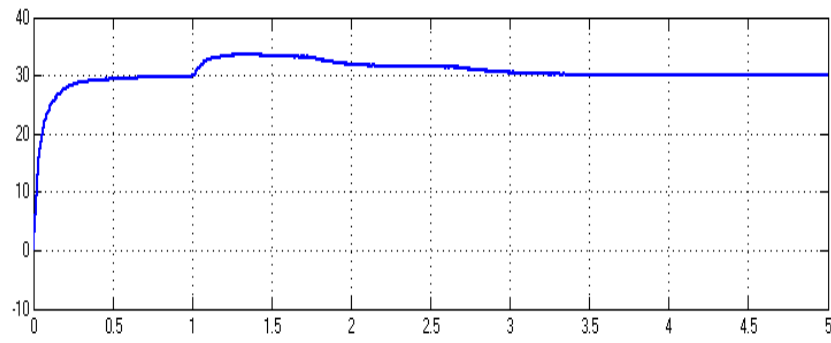

Figu-10 '-Output-voltage-across-R-Load of-BDABDC-DC'

'-Output-current-through-load' is delineated in Fig- $11 \&$ its-value is $0.056 \mathrm{~A}$.

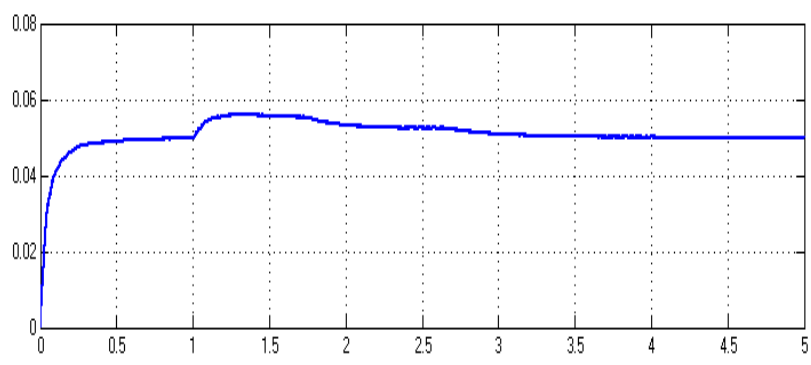

Figu-11. '-Output-current-through-load'

'-Output-power' is delineated in Fig-12\&its value is $1.9 \mathrm{~W}$.

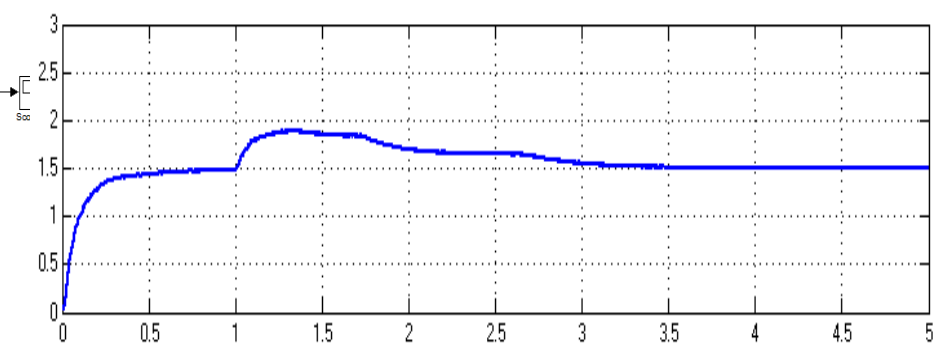

Figu-12.' -Output-power'

C-Closed-loop-BDDABDDC-with-FOPID-controller

Figu 13 shows the "-Closed-loop- BDABDC-DC with FOPID-controller". The value of voltage across the load is measured and evaluated with VRef. Comparison of these two parameters is the error which is fed to FOPID Controller. Response of FOPID is used to update the pulse-width of lower-MOSFETs

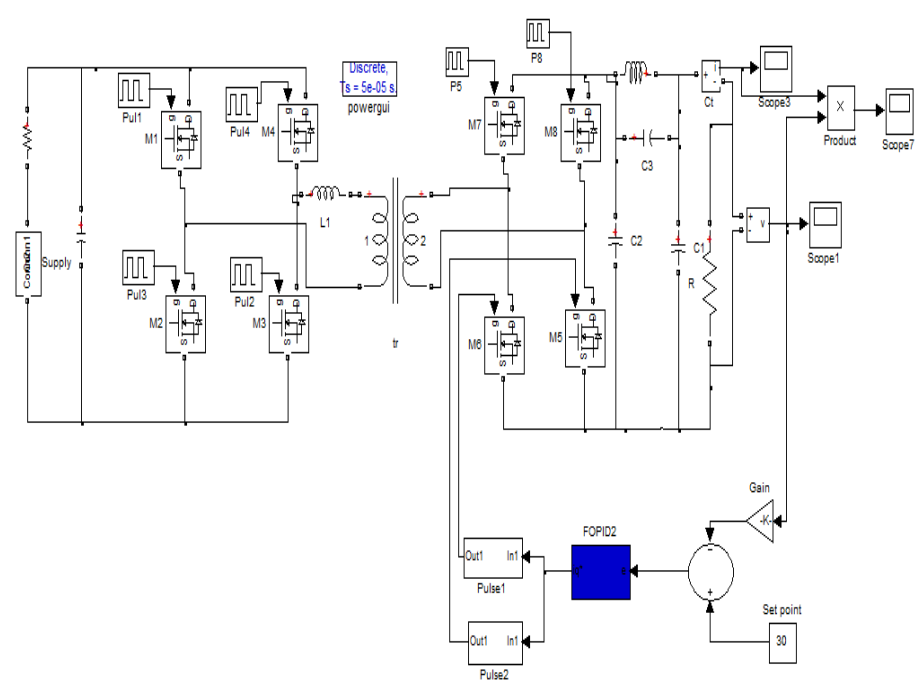

Figu-13.BDABDC-DC's closed loop with FOPID-controller'

Fig 14 shows the Voltage value at the input side which is $18 \mathrm{~V}$.

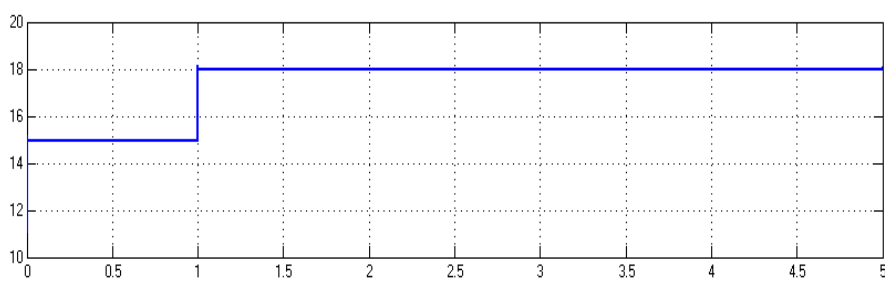

Figu-14. '-Input-Voltage'

'-Output-voltage-across-R-Load' is delineated in Fig-15\&its-value is $34 \mathrm{~V}$.

Published By

Blue Eyes Intelligence Engineering \& Sciences Publication 


\section{Enhanced 'BDABDC-DC' System For Vehicle To Grid Technology}

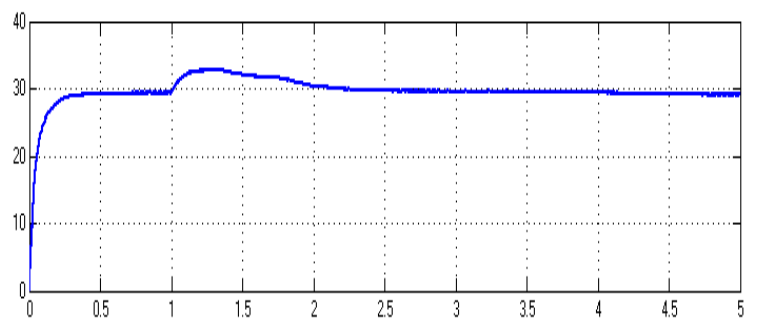

Figu-15. '-Output-voltage-across-R-Load'

'-Output-current-through-load' is delineated in Fig-16\&its-value is $0.056 \mathrm{~A}$.

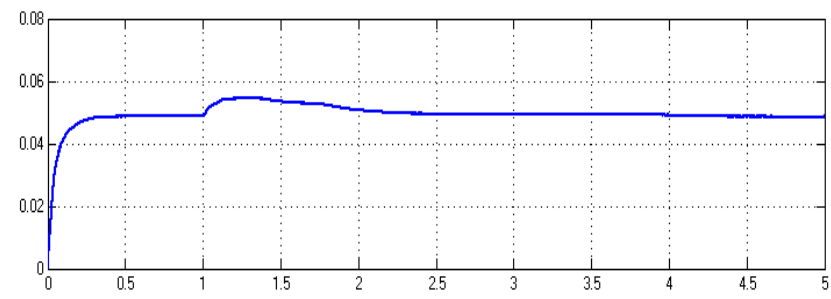

Figu-16. '-Output-current-through-load'

'-Output-power 'is delineated in Fig-17\&its-value is $1.8 \mathrm{~W}$.

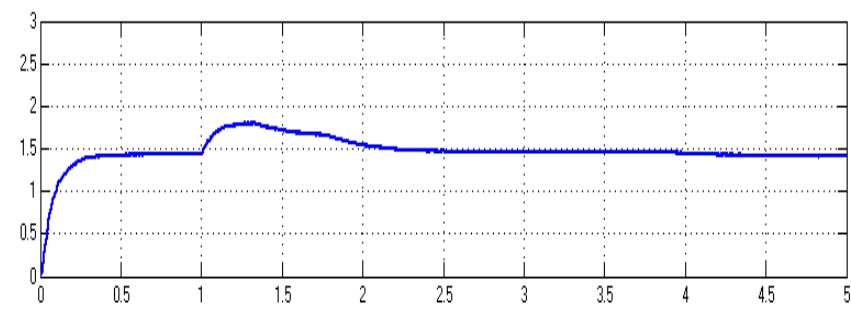

Figu-17. '-Output-power'

Table 1 clearly indicates the analyzed responses of both PI \& FOPID Controllers in BDABDC-DC system. It is seen, By using FOPID-controller, $\operatorname{Tr} 1(\mathrm{~s})$ (Rise time) gets decreased from $1.3 \mathrm{sec}$ to $1.2 \mathrm{sec} ; \mathrm{Tp} 1(\mathrm{~s})$ (peak-time)decreases from $1.6 \mathrm{sec}$ to $1.4 \mathrm{sec}$; Ts1(s) (settling-time)decreases from $3.0 \mathrm{sec}$ to $2.2 \mathrm{sec}$;Ess1('steady-state-error') decreases from $0.70 \mathrm{~V}$ to $0.32 \mathrm{~V}$.

Table -1 Analysis of the responses Using PI \& FOPID Controllers

\begin{tabular}{|c|c|c|c|c|}
\hline $\begin{array}{c}\text { Types of } \\
\text { controller }\end{array}$ & $\operatorname{Tr} 1(\mathrm{~s})$ & $\operatorname{Tp} 1(\mathrm{~s})$ & Ts1(s) & Ess1 \\
\hline PIcontroller & 1.3 & 1.6 & 3 & 0.7 \\
\hline FOPID & 1.2 & 1.4 & 2.2 & \\
\hline
\end{tabular}

\section{CONCLUSION}

In this work, simulation of closed loop -BDDABDC-DC with' PI and FOPID controller' is done and the outcomes are evaluated .It is analyzed when FOPID controller is used,Ts,Tr,Tp \& Ess are getting decreased which can observed from the above Table-1.The evaluation implies that for the proposed converter the 'dynamic response's improved using 'FOPID Controller'. The present work deals with only comparison of closed loop-BDDABDC-DC with 'PI' and
'FOPID' controller. 'Proportional Resonant controlled converter 'can be implemented in the next stage of the work.

\section{REFERENCES}

1. Zhang,-Zhe; -Tomas-Manez,-Kevin; -Xiao,-Yudi; -Andersen, -MichaelA.E. "-High-voltage -gain-dual-active-bridge-converter-with an-extended-operation-range-for-renewable-energy- systems"in-proc..,-of-2018-IEEE-Applied-P.E.-Conf..,\&-Exposition-IEEE.-DOI : 10.1109/-APEC.2018.8341271.

2. BiaoZhao,-QingguangYu\&-WeixinSun,“-Extended-phase-shift-contro -of-isolated-bidirectional-DC-DC-converter-for-power-distribution-inmicro-grid",-IEEE-Trans.., -on-PE, -Vol- 27, -NO-1-Nov-2012

3. YuxiangShi,-RuiLi,-YaosuoXue,\&HuiLi,"-Optimized-operation-of-cur rent-fed-dual-active-bridge-DC-DC-converter-for-PV-applications”,-I EEE-trans..,--on-I.E, -vol-62, -no-11, -nov-2015

4. Tibola,G.;-Duarte,J.L."-Dual-two-stage-isolated-bidirectional-DC-DCconverter-for-DC- grid-storage",-in-IEEE E-CCE -Asia -the-International-P.E-Conf..,-Niigata(JPN),-20-24-May-2018 (-pp-1447- 1454)

5. J.Riedel,“-On-frequency-domain-analysis-of-dual-active-bridge-dc-dcconverters”.-Ph.D.thesis, RMIT-Melbourne, -Dissertation,-Mar-2017.

6. BiaoZhao ;-QiangSong ;-WenhuaLiu ; -YandongSun,“-Overview-of-du al-active-bridge-isolated-bidirectional-DC-DC-converter-for-high-freq uency-linkpower-conversion-system"-IEEE-Trans..,-on-P.E(-Volu--29 ,-Issu- 8, -Aug- 2014 )

7. C.T.Ma,"-Design\&-implementation-of-a-bidirectional-DC/DC-convert er-for-BESS-operations", -proce..,-of-the- inter..,- multi-conf.., of-engineers \&-computer-scientists-2017-vol-II, -IMECS-2017, -Mar-15 - 17, 2017, -Hong-Kong

8. WeldayGebremedihnGerekial,“-Bi-directional-power-converters-for-s mart-grids",-Masterof-science-in-electric-power-engineering, -jun-2014.

9. -K.sowmya,-K.S.Ravikumar,“-A-review-on-bidirectional-isolated-dcDC-converter-in- electric-vehicle”, -inter..,- jour..,-of -engi..,-tech, -management \&-applied-sciences-jun-2017, -volu-5,- issu-6, ISSN-2349-4476

10. HaihuaZhou,-SiewTuckSing,-TranDuong,-A.M.Khambadkone,"-Interl eaved-bi-directional-D-A-B-DC-DCconverter-for-interfacing-ultracap acitor in-micro-grid application" -Aug-2010

-DOI- 10.1109/ISIE.2010.5636841 ·-Sour-IEEE-Xplore-Conf..,:-I.E(IS IE), -2010 -IEEE-Inter.,-Symposium-

11. NishaKondrath,"-An-overview-of-bidirectional-DC-DC-Converter-top ologies\&-control-strategies-for-interfacing-energy-storage-systems-inmicrogrids"-Journal-of-electr..,-engi6 doi-10.17265/2328-2223/2018.01.002

$(-2018) 11-17$

12. Yihua $\mathrm{Hu},-$ Weidong Xiao,-Wenping Cao, -Bing Ji,-D.JohnMorrow, "-Three-port-DC-DC-converter-for-stand-alone-photovoltaic-systems", -IEEE-Trans..,-on-P.E,-May-2014.

13. VenkateswaRaoP,-SKMujiburRahman“-Grid-connected-pv-system-usi ng-current-fed-dab-dc-dc-converter-based-cascaded-multilevel-inverte r-with-low-frequency-ripple-free-MPPT", $\quad$-Intern..-jour..,- $\quad$ of -science,-engg \&technology- research (IJS-ETR)-Vol- 7, -Issu-7, -Jul-2018, -ISSN-2278 -7798.

14. Madasamy,-Ramadas,"-A-novel-DC-DC-converter-based-integration-o f-renewable-energy - sources-for-residential - micro - grid-application s",-interna..,-jour..,-of-innovative-research-in-science,-engi..,\&-tech..,vol.-6, -issu-9, -sept-2017

15. AngelGuillermo-Hidalgo-Oñate,"-Design-of-an-isolated-DC/DC-power -converter-to-connect-a-low-voltage-super-capacitor-string-to-a-DCpower-system", -The-university-of- Nottingham-Sept-2016

16. J.Kim,-I.Jeong,\&-K.Nam,“-Asymmetric-duty-control-of-the-dual-activ e-bridge-dc/dc-converter-for-single-phase-distributed-generators,"-in-I EEE-energy-conversion-congress\&-exposition(ECCE), -pp-75-82, -Sept-2009.

17. H.Plesko,-J.Biela,\&-J.Kolar,“-Novel-modulation-concepts-for-a-drive-i ntegrated-auxiliary-dc-dc-converter-for-hybrid-vehicles,"-in-IEEE-app lied-P.E-Confe..,\&-Exposition(AP-EC),-2009,-pp-164-170,-Feb-2009.

18. A.Jain\&-R.Ayyanar,“-PWM-control-of-dual-active-bridge:comprehensive-analysis\&-experimental-verification,"-in-34th-AnnualConf..,-of-IEEE-I.E(IE-CON), -2008, -pp-909-915, -Nov-2008.

19. A.Jain\&-R.Ayyanar,“-Pwm-control-of-dual-active-bridge:-Comprehen sive-analysis \&-experimental-verification,"- IEEE-Trans..,- $\quad$ on-P.E -vol- 26, -pp-1215-1227, -Apr-2011. 
20. J.Kim,-H.-S.Song\&-K.Nam,“-Asymmetric-duty-control-of-a-dual-halfbridge-dc/dc-converter-for-single-phase-distributed-generators,"-IEEETrans..,- on-P.E,- vol.-26,- pp-973-982, -Mar-2011.

21. Y.Wang,-S.W.H.deHaan,\&-J.A.Ferreira,"-Optimal-operating-ranges-of -three-modulation-methods-in-dual-active-bridge-converters,"-in-IEEE -6th-Internat..,-P.E\&-motion control-confe..,(IPE-MC), -2009, -pp-1397-1401, -2009.

22. GG.Oggier,-G.O.Garcia\&-A.R.Oliva,"-Switching-control-strategy-tominimize - dual-active-bridge-converter-losses,"-IEEE-transa..,-on-p. E, -vol-24, -pp-1826-1838, -Jul-2009.

23. R. De Doncker, D. Divan, and M. Kheraluwala, "A three-phase soft-switched high-power density dc/dc converter for high-power applications," IEEE Transactions on Industry Application, vol. 27, pp. 63-73, Jan./Feb. 1991.

\section{AUTHORS PROFILE}

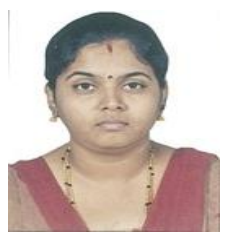

N.Janaki received B.E degree from the Department of Electrical and Electronics Engineering, from Anna University, Tamil Nadu, India in 2010. She got M.Tech (Power Electronics) degree from Sastra University, Tanjore; TamilNadu, India in 2012.She is a Part time Research Scholar at Vels Institute Of Science Technology And Advanced Studies, Chennai, Tamil Nadu, India. Her Area Of research interest is Power Electronics and Drives.

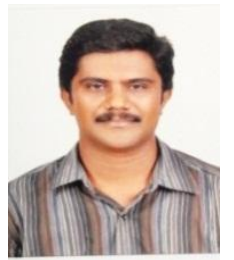

Dr. R. Krishna Kumar received $\mathrm{PhD}$ degree from Anna University, Chennai. He is currently working as a Professor/Head in the department of Electrical and Electronics Engineering, at Vels Institute of Science Technology And Advanced Studies, Chennai, Tamil $\mathrm{Nadu}$, India. He has sixteen years of working experience. He is a member in SAEINDIA.His area of research interest includes Unmanned Aerial Vehicle (UAV) and Power Electronics and Drives 